\title{
TARGETING RURAL POVERTY IN SUB-SAHARAN AFRICA: A POVERTY ALLEVIATION POLHCY FRAMEWORK WITH PARTICULAR REFERENCE TO CAMEROON.
}

\section{By}

\section{TCHAKOA JONAS}

Faculty of Economics and Management University of Dschang - Camerọon
AJAGA NJII

Facuity of Agriculture

University of Dschang - Cameroon

\section{INTRODUCTION}

As far back as 1950, Eugene Black, then President of the World Bank suggested that "...if during the last hundred years greater effort had been devoted towards improving conditions in less developed areas of the world, we might not today be witnessing so much social unrest and possibly not even hostilities... It is the existence of widespread poverty and misery which has stimulated the spread of the virus now threatening the peace of the world".

After r.early fifty years, these remarks are still pertinent today and even more pertinent for today's African countries than when they were made. Current African experience with development indicates that poverty alleviation remains the greatest challenge facing African leaders, scholars and philosophers. Due to persistent social and cultural obstacles aided by backward-looking policies, the Quality of Life in SubSaharan Africa does not appear to be improving as well as in other developing regions (e.g. the tiger economies of Asia).

For instance, in a recent assessment of the African situation, the World Bank (1998:37) reported that public spending in Tunisia is not equitable and not targeted as it should to the poor. The bottom $20 \%$ of the Tunisian population is receiving less than $15 \%$ of total public expenditures, whereas the top $20 \%$ receives almost $29 \%$ of expenditures. The report concludes by expressing the need to improve access to resources for the poor in Tunisia through improved screening in the process of identifying the poor and the allocation of national resources. 
Resource allocation and targeting is crucial for Sub-Saharan Africa, another World Bank (1996:2) report states, because all standard measures of poverty show that approximately $50 \%$ of the population in Sub-Saharan African countries live below the poverty ine -- a poverty gap that is among the highest in the world except in South Asia.

Eugene Black"s (1950) assessment implies three assumptions:

1) that the persistence of widespread poverty in Africa poses a serious threat to the socio economic stability of the continent;

2) that poverty alleviation, though difficult to achieve, is NOT impossible; and.

3) that development efforts in Africa must be targeted to achieving poverty eradication.

One key lesson learned after nearly 50 years of poverty reduction efforts and which the present paper intends to explore is that approaches hitherto adopted in combating poverty have incurred high opportunity costs: the happiness of a small minority of Africans has been achieved on the backs of the vast majority of the poor. Thus, Africa's «white elephants» are the product of misguided technology, inappropriate policies and above all, an epitomy of the neglect of sociological and cultural factors in the conceptualization and execution of development programmes on the continent.

Generalized subsidy schemes intended to benefit the poor for instance permeated the development landscape for two decades (1960-1980). Blanket policies cum treatments to the poverty "cilisease» were the order of the day in development economics. For example, industrialization, import substitution, price stabilization funds, and integrated rural development were some of the theoretical constructs and models propounded by economists, sociologists, anthropologists and political scientists between 1950 and 1975 .

After 1975, developmentalism as a means to achieve poverty alleviation, and to fight ignorance and disease in Africa, was replaced by draconian adjustment policies. As Baeck (1993:3-4) states: "the debt crisis of the 
developing countries in the 1980 s that reinforced structural adjustment, and stabilization policies became chapter and verse in theory formulation as well as in practice".

This paper proposes a methodology for identifying and reaching the poor. The framework proffered here is a contribution to the on-going debate on poverty alleviation. The approach consists of two mutually reinforcing elements : resources and programmes. Limited ressources must be targeted to those who need them most. Poverty reduction programmes must be decentralized in such a way that they can be closely monitored and the services equitably delivered. Both elements go together.

The main thrust of our argument is that rather than rely on general transfers and other indirect mechanisms, governments can make higher achievements in poverty reduction by locating the poor and targeting them in various appropriate programmes. Finally, the factors that will enable the poor to escape poverty are systematically delineated and addressed within a Poverty Policy Framework.

The prevailing economic crisis in Cameroon and the draconian measures taken to combat it through Structural Adjustment Programs (SAP) have made things worse by aggravating social inequality whose effects weigh more on the more vulnerable segments of the population such as women, children, rural residents, farmers, urban unemployed and the physically handicapped.

Because of the seriousness of the problem, much attention has been shifted in recent years by both national and international communities to direct blind and blanket attacks on poverty without adequately analyzing the who, what, where and how of poverty. However, it is heart-warming to note the World Bank's recent (1995) efforts to address these issues through its Country Poverty Assessment Studies. In this light, the following four basic questions will guide our analysis:

1) What is poverty?

2) Who are the poor?

3) Where are the poor?

4) How can the poor be effectively reached and assisted to escape the poverty trap? 
Our discussion will be articulated in three måin sections: Section I will provide a brief literature review of the main issues in poverty alleviation particularly the concept, its measurement and past strategies to reduce proverty in developing countries. Section II analyzes the targeting strategy and shows how to evaluate its performance. Finally in section III we will discuss the applicability of the targeting framework to the case of Cameroon. The conclusions will be the focus of section IV.

\section{SECTION 1: THE CONCEPT, MEASUREMENT AND STRATEGIES OF POVERTY ALLEVIATION}

\section{What is Poverty?}

Many discussions on the design of poverty alleviation policies, programmes and projects assume multidimensionality of the phenomenon and heterogeneity among the poor in both their needs and capacity to cope with poverty. It is now obvious that this approach was based on wrong perceptions and incomplete theorizing. Regardless of the society, it is unthinkable to conceive a blanket of poverty that covers everyone who is poor all of whom respond to the same motives, aspirations, circumstances, life chances, opportunities or coping mechanisms. Perhaps the prognosis that we now know of poverty alleviation strategies is the direct result of the false start in the definition and diagnosis of poverty, a concept that means many things to many people. For some, poverty is the consequence of unbalanced structural change through unmeaningful and untargeted development. For others, it is the consequence of laziness !

In his answer to the question, development for What? and for Whom? the Dag Hammarskjold report (as cited by Nji, 1981: 44) states that development should be concerned with "... every man and woman --- of the whole man and woman -- and not just the growth of things... Development geared to the satisfaction of needs beginning with the basic needs of the poor who constitute the world's majority."

Thus, development that does not target the poor cannot lead to the sustainable development of the society. The need to redesign development, 'another development' centres on the conviction that social inequalities can be removed only by targeting poverty. Development 
86

initiatives must be "geared to the satisfaction of needs, beginning with the eradication of poverty." (Dag Hammarskjöd report, 1975: 28) ${ }^{1}$

Poverty is not easily defined as can be seen from the plethora of definitions in existing literature. But the most widely accepted definition which we will adopt in this paper is the one that relates poverty to minimum survival needs of people in what is generally described as the "basic needs approach" (Nji, 1981; Thirlwall, 1983; Meier, 1984). According to this approach, an individual can be said to be poor if he or she is unable to satisfy his or her basic minimum survival needs.

As with any other definition of poverty, the difficulty with this definition lies in the meaning of "minimum needs" and how much money is needed to satisfy these needs. For the purposes of this paper, we will define "minimum needs" as the basic essential requirements of existence without which life is unliveable. These "essentials" include food, shelter. clothing and good health. These needs can be met either in-kind or incash with the understanding that a minimum amount of cash is required to meet those needs. To the extent that such an amount is determined, d? constitutes what is called a 'poverty threshold' or 'poverty line', a level below which human survival becomes impossible, and is thus considered 'poor'.

\section{Approaches to Poverty Alleviation}

Three main approaches have been used to attack poverty: i) through economic growth, ii) through specific programmes designed to increase the incomes of the poor and, iii) programmes targeted to meet the basic needs to the poor. The first two approaches are related to incomecentred measures of poverty while the third is related to the basic needs measure.

\section{Economic Growth Approach}

In their treatise, "Redistribution with growth" Chenery et al. (1974) argued that poverty can be reduced if development programmes are designed to address the needs of the poor and development policy re-oriented towards poverty-focused strategies. While recognizing the need for more direct measures of poverty alleviation, they emphasized that for a lasting

${ }^{1}$ Dag Hammarskjöld, 1975. What Now. Development Dialogue Uppsala, Sweder. 
impact on poverty, redistributive policies have to be consistent with and conducive to growth-promoting policies. According to Pscharopoulos (1990), general economic growth is the most effective way to attack poverty in the long-run by increasing opportunities for employment. But he notes that this may take a long time for income growth to trickle down to particular groups in the population.

Furthermore, it can be argued that the effect of growth on poverty is generally lower in Sub-Saharan Africa than in other regions such as East Asia. The deficit in the quality of life in Sub-Saharan Africa is due, largely to relatively high levels of population growth, lower capacity for capital accumulation by the poor, high levels of inequality and a host of African cultural practices that negate development efforts. The culture of colonialism has had its fair share of the blame (Baeck, 1993; Boer et al., 1985; Nji, 1981).

\section{Specific Programmes Approach to increase opportunities for the poor}

It is argued here that beyond general economic growth, the worst aspects of poverty such as food deficit and malnutrition could be tackled at a faster pace by increasing the stock or productivity of the physical assets of the poor through land reform, irrigation and credit schemes for farmers. Higher productivity can be achieved through education, training and indigenous capacity building that recognize the important role that values, customs, beliefs and human institutions play in human tevelopment.

-n any poverty alleviation strategy, better incomes should be seen not as an end in themselves but as means to an end. This is because the ultimate utility of incomes is to facilitate the access of poor people to those goods and services required to meet minimum or basic needs (e.g. food, health care, shelter, education, etc.). This is likely to be easily achieved through the targeting approach.

\section{The Targeting approach to poverty alleviation}

In this paper, we define targeting as a process of designing policies, programmes and projects aimed directly at improving the standard of living, the life expectancy and increasing opportunities for targeted segments of the population with the highest level of unsatisfied Dasic 
needs. Targeting is achieved through the creation of opportunities to produce more and better quality food, improvements in nutrition, primary health care, access to potable water, education and employment.

Since the advent of the so-called 'economic crisis in Cameroon, the government has timidly adopted the targeting approach but for the wrong reasons: shrinking budgets and paternalistic politics. But the key consideration in targeting is to maximize the flow of benefits to intended beneficiaries while keeping the administrative costs low. Such interventions are certainly effective instruments in combating poverty in the short run if they are pursued with rationality, reason and objectivity (Pscharopoulos, 1990).

\section{Measuring Poverty}

The initial step for an effective approach to poverty alleviation ought to consist in trying to measure it so as to determine its scope and impact for different groups of people, a region, or even for the same population at different times. The next thing to do is to explore the causal relationships connected with the emergence and persistence of poverty. In a sense, we ought to find answers to Lipton's (1977) question :" Why Po $r$ People Stay Poor".

Nespite several unresolved issues so far, the measurement of poverty has made considerable progress in the literature. Also, analyses of the dynamics of poverty have become more sophisticated since the late 1970 's when the simple head-count measure was the determinant mode of aggregation (Bardhan, 1995).

By and large, measures of poverty commonly cited in recent literature can be grouped into two broad categories: the income-centred measures and the basic needs measures.

\section{Income-centered measures of Poverty}

The standard approach to the measurement of poverty proceeds by comparing the annual income (Yi) an individual or groups (i) has available to spend to a designated per capita income level $(z)$ called poverty line. An individual (or group) is considered poor if $Y i<z$. This is known as the absolute income measure of poverty. The most common 
policy option to redress disequilibruim between $Y$ and $Z$ is to encourage income growth among the poor or adopt income redistribution measures.

A second uncome approach to measure poverty consists in analyzing poverty in terms of relative incomes. That is, the share or percentage of national income that a group of people or a region receives as can be measured by the Lorenz Curve. This approach means that although there may be enough income to go around within a country such as "ameroon, enough of it is not equally distributed so that some people "e forced to live with less money than is needed to satisfy basic needs. sople living under these circumstances can be considered to be living in Jverty. The policy option often adopted in this case is to advocate for income distribution or redistribution from the non-poor to the poor.

The third income measure is the poverty-Gap Index (Ravallion and Huppi, 1991). This measure is obtained by calculating the difference between each individual's income and the income indicator of the poverty-line (z-yj) to obtain an average poverty-gap index. The index thus obtained is expressed as a proportion of the poverty line.

The poverty-Gap Index as an income measure has an advantage over e other two in that it is sensitive to changes in the income levels of the spulation over time. Since income shifts necessarily cause changes in e level or degree of poverty among individuals, the Poverty Gap index bound to shift as well in response to changes in incomes in the opulation.

The fourth but also the most interesting income related measure of poverty is the Foster-Greer-Thorbecke (FGT) measure (1984). This measure is sensitive to differences in the severity or depth of poverty. The model starts by the choice of a parameter ( ) and moves to build a distributionally sensitive measure given by

$$
\mathrm{Pa}=\frac{1}{n} \sum_{j=1}^{q}(g j / z)^{\mathrm{a}}
$$

Where: $P=$ the aggregate poverty index

$n=$ the total population size

$q=$ the number of poor people

$g j=z-y j$ or the poverty - gap for individual $j$ 


\section{For example:}

$z=$ the poverty line

$a=$ the measure of the severity or depth of poverty

The larger $a$ is, the greater the severity of poverty.

$Y$ and $z$ are defined as above

if $a=0, P_{0}=q / n$ which is simply the head-count index that shows the number of poor people as \% of the population.

if $\mathrm{a}=1, \mathrm{P}_{1}=\frac{1}{n} \sum_{j=1}^{4}(g j / z)$

which is the average poverty-gap in the population expressed as a proportion of the poverty line.

If a $>1, \mathrm{~Pa}$ is then sensitive to the distribution of income among the poor. It indicates a decrease in aggregate poverty if a transfer of income is made from a less poor to a poorer person.

Equation (1) then has the advantage of allowing for the calculation of the other income measures depending on the value of .

More interestingly, the Foster-Gréer-Thorbecke (FGT) measure $(\mathrm{Pa})$ is decomposable additively by population sub-groups so that aggregate poverty level $(\mathrm{Pa})$ can be expressed as a weighted sum of poverty levels of the various component sub-groups of the population according to the following equation:

$$
P_{a}=\sum_{i=1}^{m} \text { Pai } \frac{n i}{n}
$$

Where: $\quad m=$ the number of sub-groups in the population

$\mathrm{ni}=$ the size of the population of subgroup $\mathrm{i}$

$\mathrm{Pa}_{\mathrm{i}}=$ the poverty index of groups is calculated as in equation (1)

$$
\text { above for each subgroups. }
$$

These properties of the FGT measures (i.e. its sensitivity to the depth of poverty and decomposability make it the most preferred measure in targeting the poorest sub-group in a population. 
But despite their appeal, the application of income-based measures to developing countries will be very difficult for at least three reasons. Firstly, there is the lack of reliable published data on incomes. Secondly, income measures may not adequately capture some critical poverty related phenomena such as the growing informalization of economic activities. Thirdly, as Meier (1984) has noted, absolute poverty means more than low incomes and includes malnutrition, lack of education, poor health, etc. Thus, poverty analysts are increasingly recognizing the limits of income-oriented measures of poverty. The importance and validity of 'multi-faceted' measures of poverty such as basic needs (Streeten et al, 1981) also point to the relevance of cultural variables in poverty analysis.

\section{Basic Needs Measures of Poverty}

Disappointment with economic measures of poverty such as GNP or per sapita income has. shifted discussions on the eradication of poverty. According to Thirlwall, (1983), the rationale of the approach is that the direct provision of such goods and services as health, food, nutrition, education, housing, sanitation, potable water, etc. is likely to relieve absolute poverty more immediately than alternative strategies which simply attempt to accelerate growth or which rely on raising the incomes and productivity of the poor.

This focus on meeting basic human needs requires an indicator or a set of indicators by which deprivation can be judged and measured. Once identified, it is to these indicators that poverty alleviation strategies should be directed.

As a first step then, the approach requires a definition of the best indicator for each basic need. For example, the following core indicators can be identified:

Basic Needs

Indicators

1) Food and Nutrition

Per capital calorie intake as a \% of requirements

2) Health

life expectancy, infant mortality, maternal death rate 
3) Education

4) Sanitation

5) Water - supply

6) Housing primary school enrolment rate as \% of school-age children; male-female enrolments

$\%$ of people with access to health sanitation facilities

$\%$ of people with access to potable water

quality of materials used, absence or presence of latrines, no of persons per room in household Type of housing

Once defined, such basic needs indicators will serve as a useful guide to measure the relative gap between the rich and the poor and offer a view on whether this gap is widening or narrowing over time.

One of the arguments in support of this approach is that it will be difficult to help the poor in a uniform way unless their basic needs are satisfied. The gap between the have and have-nots will continue to widen unless and until the factors that keep poor people poor are identified and systematically addressed (Nji, 1981).

\section{SECTION II: THE TARGETING STRATEGY AND FRAMEWORK}

Our theoretical framework for targeting poverty begins with the assumption that the resources for poverty alleviation are limited or fixed, and that the objective is to design a poverty alleviation strategy that seeks to reduce poverty using available limited resources. To achieve this objestive, targeting will involve paying careful attention to the following three areas of our construct:

\section{a) Identifying the poor}

Since resources are limited, some priorities have to be set in approaching poverty reduction. If reliable information on individuals' earning ability is available, it is possible to identify the poor from the non- 
poor. It is also possible to classify households by per capita income or other characteristics that might qualify them for assistance.

In his recent study of poverty in Cameroon (Nji, 1994) the poor can be divided into two groups. The long-standing poor who have chronically been subjected to penury, and the 'new' poor who recently found it impossible to meet basic individual and household needs as a result of the 'economic crisis'.

\section{b) Targeting the Poor}

In a situation of resource scarcity and competing demand for services, targeting becomes a lively and feasible option. Two broad criteria can be used to determine a target group.

\section{- Targeting by geographic location}

According to Baliscan (1996), the issue of targeting in developing countries may be much simpler because the majority, and the poorest of the poor, are concentrated in agriculture or in resource-poor regions. Under these circumstances, geographic or indicator - based targeting is appropriate. Focusing on rural areas is thus a simple way to reach many of the poor.

Even within cities, geographical targeting makes sense because the poor typically live in clearly observable areas such as slums and depressed neighbourhoods.

It is in the same vein that it has been argued that rural development programs should aim at eliminating "... the pervasive and crippling poverty that reigns "among rural people in order to give them an equal opportunity for a happier life" (Nji, 1981: 44).

\section{- Targeting by Social Indicators}

Some programmes can be difficult and expensive to serve in sparsely populated rural areas. In such a situation, targeting solely on a geographical basis can lead to leakages of program benefits to the nonpoor. This is why social planners suggest using alternative criteria such as social indicators to target poverty (Wilcox et al., 1976; Mcintoch et al:; 1977). 
Based on the basic needs approach, targeting by social indicators aims at defining segments of the population made vulnerable by events of the life cycle (e.g. age) and other social deprivations that qualify vulnerable groups for specific social programmes. Such groups may include infants, school-age children, pregnant women and lactating mothers. Specific programs could include health care, nutrition, water supply, access to primary education, training, etc.

\section{ADVANTAGES OF TARGETED PROGRAMMES}

\section{i) Cost effectiveness}

Targeted programmes are cost-effective. In its assessment of povertyreduction strategies for the 1996 and 1997 fiscal years, the World Bank (1998) reports that "...targeted programs are more cost-effective and fiscally sustainable than untargeted food transfers. And that "...in general, targeting methods that impose an obligation on the recipient are best for ensuring that the program benefits only the needy" (World Bank, 1998:24).

Total budgetary costs (administrative costs and food costs) are a source of concern for governments grappling with poverty reduction programmes. Therefore, governments that adopt targeted approaches to poverty reduction can reduce costs and increase programme effectiveness by being aware of effects of costs on programme delivery. Poverty-reduction programmes that have work requirements or other obligations such as sending children to school are seen to be more costeffective than food rations (World Bank, 1998:24). Thus, a cost-sensitive approach ensures that the programmes are targeted only to needy groups or individuals who have been pre-determined on the basis of selected social, economic and cultural indicators.

\section{ii) Avoidance of Leakages of Benefits}

The main draw-back of generalized poverty alleviation programs is that the benefits of the programs are bound to leak out to unintended groups in the population. For instance, when a general food subsidy is given for food items assumed to be consumed mainly by the poor, richer groups of the population are likely to also consume the same food, taking advantage of the subsidy. But a food aid programme that is well 
designed and targeted to well-defined groups of beneficiaries, can minimize leakages.

For example, by targeting food supplements to particularly vuinerable groups such as pregrant or lactating women, or designing clinic-based programmes that combine health inputs and nutrition supplements using participatory methods, leakages to the non-poor can be avoided.

Food aid to developing countries is a case in point. In Cameroon, cans of fish and edible oils, as well as bags or rice and bales of blankets intended for the poor end up in the kilchens of powerful politiclans and other privileged individuals in the society. Sometimes it is wealthy business men who buy the Food Aid items and sell them in their shops (under the counter but most often in broad day light) at high profits.

Rural development projects that were intended to benefit the poor were found to be the 'dairy cows' or what the Cameroon government officials themselves described as the «milking cows» of privileged government appointed managers ( $\mathrm{Ni}$, 1986). Good targeting programs are likely to decrease these leakages considerably, if they are accompanied by good management grounded in morality and a little conscience.

\section{Designing Targeting Policies}

The main question here is that of selecting an efficient targeting policy instrument. The set of policy instruments available for the alleviation of poverty is often quite restricted. In rural areas imperfect information on the true living standard of potential recipients and on the performance of specific poverty reduction programs limit the efficiency of a targeting strategy.

In the final analysis, the concern should be to show how limited resources available for poverty alleviation can be allocated. This can be done through an institutional approach to targeting policy. According to this approach, the question of why poverty alieviation programmes do or do not work has much more to do with social institutions than with policy design. Anti-poverty policies often fail because administrative incompetence and corruption keep governments from delivering the goods. (Nji, 1992). Under these circumstances, designing and implementing effective targeting policies would include: 
1) concentrating poverty reduction initiatives on programmes with high multiplier effects or with economies of scale (e.g. public works, infrastructure development, health improvement programmes, education, nutrition, and low-cost housing).

2) decentralizing poverty action by promoting local selfadministered institutions and participation in the design, implementation, and monitoring of poverty alleviation programs;

3) Empowering local groups, micro enterprises and NonGovernmental' Organisations (NGO's) who are known to work very closely at the grassroots with a strong advocacy stance in favour of the poor.

Bringing morality to bear on policy-makers so that corrupt and inefficient government agents are excluded from poverty reduction programmes. Transparency and accountability should be the corner-stones in the implementation of public policies. In this exercise, concrete steps will have to be taken to empower women and the poor in the decisionmaking process on programmes and projects.

\section{Measuring Targeting Performance}

The central concerns in targeting policies are participation, accountability, programme efficiency and cost-effectiveness in reaching the' poor. While cost is important, care must be taken to ensure that programme effectiveness is not jeopardized by economic concerns with costs. Careful programme design ensures that a combination of social, economic, cultural and political considerations is taken into account to increase programme effectiveness while reducing costs. These indicators are also crucial in measuring the targeting performance of poverty reduction programmes.

A good test of the effectiveness of a targeting programme consists in comparing the distribution of income among participants in that area with that for the whole population in the area. This is illustrated on fig. I. 
Figure 1 illustrates an income distribution test for targeting performance. It gives cumulative income distributions for the entire population as a whole (full line), for programme 1 participants (dotted line B) and for programme 2 participants (dotted line $C$ ). For each income level on the horizontal axis, there is a corresponding point on each curve giving the cumulative percent of households (vertical axis) whose incomes fall below that level. For example at an annual income level of $20000 \mathrm{Fcfa}$, (US\$40) curve A shows that in the whole population $60 \%$ of households. earn incomes below that level while curves B and $C$ show $80 \%$ and $25 \%$ respectively in the areas from which they are dawn.

In terms of targeting success and assuming an annual poverty income of $20000 \mathrm{Fcfa}$, we can draw the following conclusions concerning the relative performance of program 1 (curve $\mathrm{B}$ ) and program 2 (curve $\mathrm{C}$ ).

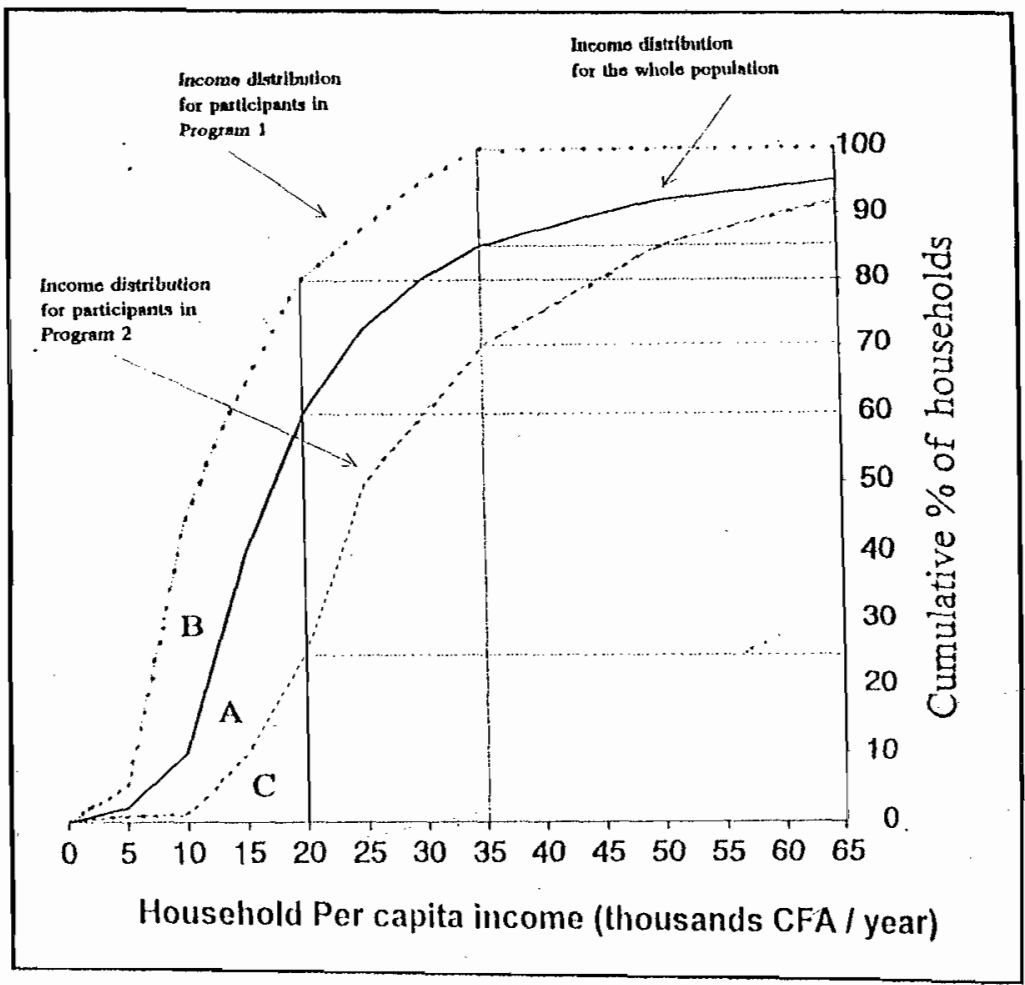

Figure 1. Targeting performance of two poverty - oriented programs: Income distribution for the 2 programs and the population as a whole. 
- Programme 1, (geographic targeting) has been quite effectively targeted towards a poor area as the income distribution of the participants includes $80 \%$ of poor people compared to $60 \%$ for the whole population. The curve also shows that no household has an annual per capita income above 35000 Fcfa (or US\$50), meaning that if the poverty threshold were fixed at that income level, all the households in this region will be considered poor. From this analysis, the region will be considered a poverty-stricken area.

- Programme 2, in contrast is very poorly targeted as its targeted area includes only about $25 \%$ of the poor. However, only about $75 \%$ of the households are likely to be considered poor, if the poverty line is fixed at $35000 \mathrm{Fcfa}$ compared to about $85 \%$ in the whole population and $100 \%$ in the area of program 1 . This area cannot be considered a poor region following the criteria of a relative income indicator.

These conclusions remain true no matter where one draws the poverty line on the figure. Our theoretical framework posits that poverty reduction can be achieved through careful policy-making guided by morality in public administration.

\section{SECTION III: APPLICATION OF TARGETING APPROACH TO POVERTY IN CAMEROON}

In Cameroon, like in many African countries, poverty has meant more than income inequality (or relative poverty). We are concerned here with abject poverty, a condition of listlessness which threatens the survi:al of people. In this situation, people are inadequately fed, poorly clothed and sheltered. They simply are incapable of satisfying basic biological needs for survival. One important feature of the poverty profile $n$ Cameroon is that the incidence of poverty is much higher in some families, groups of people and regions than in others. This makes targeting easier and more effective if the poverty reduction programmes were to be well and carefully designed.

The Participatory Poverty Analysis (PPA) for Cameroon (Nji 1994; World Bank, 1995) shows that the majority of Cameroonians in 1994 were unable to meet their basic needs as a result of either unemployment, limited opportunities, the negative effects of the devaluation of the CFA 
Franc or a combination of all these factors. Two types of poverty groups were identified. Those affected by 'structural' poverty which pre-dates the economic crisis of the $1986-90$ period reflecting inequalities in the past patterns of economic development.

\section{These were the long-standing poor}

The second group consists of the 'new' poor, a creation of the economic crisis itself. The poor in this group began to feel the effects of poverty in 1986 due to a sharp decline in commodity prices on the World Market. Coffee, cocoa and rubber farmers are the most represented in this group as well as persons who depend on the spill over from the trade on commodities. Massive retrenchments in the public and private sectors and salary cuts of up to $70 \%$ for civil servants and University Professors contributed to a marked fall in the standards of living of civil servants.

The PPA further indicates that poverty in the cities of Yaounde and Douala was aggravated by structural unemployment in the public and private sectors while in the East and Far North provinces, poverty is accentuated by geographical isolation from the country's economic centre in Douala $(1500 \mathrm{~km}$ ) and the political centre in Yaounde (1 200 $\mathrm{km})$.

Using a participatory assessment approach, the poor associated their misery with hunger, as many families reported living on one meal a day. They faced dietary inadequacies as well as high expenditures on food, medical care, education and housing. Powerlessness and lack of 'voice' were also highlighted by the poor. The poor in all the five regions studied distinguish themselves from the non-poor on five main criteria:

1. the presence of hunger in their households;

2. fewer meals a day and nutritionaliy inadequate diets;

3. higher percentage of their meagre and irregular incomes being spent on food;

4. non-existent or low sources of cash income;

5. a feeling of powerlessness and their viability : make themselves heard ( $\mathrm{Nji}, 1994)$. The poor reported that they 
have been forced by prevailing circumstances to adopt various strategies to cope with poverty. The major forms of adaptation reported were: a) self medication; b) recousse to traditional medicine (herbalists and sorcerers); c) prostitution; d) cheating in exams and e) corruption.

As the results of the PPA indicate, poverty cannot be measured by income profiles alone. The quality of life, cultural variables and the psychological state of individuals must be considered in the poverty equation. These qualitative data turther illustrate the need to attack poverty using qualitative and quantitative data and the using of a targeting approach to poverty alleviation.

\section{Income measure of Poverty in Cameroon}

From our definition of poverty as the inability to attain a minimal standard of living, and considering the poverty line index suggested by the World Development Report (1995) covering an income range of 275-370 US dollars per person per year, we can conclude that an overwhelming majority of Cameroonians live below the poverty line. After the 1993 salary cuts, and the devaluation that followed in 1994, a University professor now earns in 1994 only $70 \%$ of the 1980 salary. The majority of them now earn annual incomes of less than US\$3000, compared to an average annual salary of US $\$ 24000$ at the pre-devaluation prices!

\section{Social Indicators, Poverty Measurement and Reduction}

Biderman (1970) suggests that social indicators can be useful in at least three contexts...information, intelligence, and enlightenment. At the informational level, social indicators can facilitate the day-to-day operation of social organizations. For example in recording the number of public complaints received by the police, or water and electricity corporations (Sheldon and Parke, 1974). Social indicators for 'intelligence' would be used in management. For example, specifying the number of fire men available at any given time to fight a bush fire. Social indicators for enlightenment may be used in policy formulation.

For instance, the number of people who receive food aid classified by their socio-economic characteristics. Based on these three functions, social indicators as social statistics are useful tools in problem identification and decision-making. 
Social indicators that can be used to measure the incidence of poverty include age, gender, health, nutritional level and other ethnic characteristics. Generally, high infant mortality, poor health and nutrition, limited education are characteristics of poor nations and peoples. Living conditions as measured by housing standards as well as access to public social amenities such as health care, education, potable water are indicators of poverty.

In Cameroon, like in most African country, poverty is both person and location-specific. As Nji, (1994) states, the poor in Cameroon are to be found in rural areas as well as depressed neighbourhoods in the cities of Douala, Yaounde, Maroua, etc.

They suffer from malnutrition, high disease prevalence and live in makeshift shelters. They are unemployed, illiterate and voiceless. They have no access to good health and sanitation services because they cannot afford to pay for the costs. In the words of a poor respondent from one of the provinces, «... sometimes the water is brown. We call it tea, but we drink it anyway, as there is nothing else to drink " (Nji, 1994).

\section{Resources, Region and Poverty}

As has been stated earlier, poverty can be location-specific. Resource endowments, geographical location can and do influence the life chances of individuals. In a recent study of the Mandara Mountains Region of the Far North Province of Cameroon (Nji and Fouteh, 1998), peasant indicators are waiking on a thin thread of life and death. Lack of water, soil erosion and soil infertility are at the root of their poverty and persistent misery.

Illiteracy, a dominant-feudal structure and a crippling tax system conspire to make the mountain cultivators foor and voiceless. Natural factors such as climatic conditions and man-made constraints such as unresponsive. political systems are at the root of poverty in several regions in Cameroon.

Yet, Adam Smith (1983) had predicted that «little else is requisite to carry a state to the highest degree of opulence from the lowest state of barbarism, but peace, easy taxes and a tolerable administration of justice $»$. In this view, development is retarded. by moral passions and 
well served by material interests such as corruption and greed (Blaeck, $1993: 13$ )

By and large, there is a host of physical, economic, and socio-cultural factors that interact to maintain the persistence of widespread food insecurity and poverty in Cameroon. Food insecurity, high rate of illiteracy, high infant and maternal death rates, lack of access to potable water and deteriorating sanitary and housing conditions are some of the social indicators of poverty in North Cameroon for instance. From a gender perspective, it is also in the Northern Provinces that women are systematically pushed into poverty by crippling socio-cultural barriers to personal growth. As $\mathrm{Nji}$ and Fonteh (1998) note, women have no land rights nor protection against exploitation by the powerful male-dominated elite.

Using the above brief analysis of poverty in Cameroon, we suggest that poverty can be reduced in Cameroon or any other country by effectively targeting vulnerable poverty groups. Such targeting should take into account not only the individual characteristics of the poor but also the structural conditions that make and keep the poor.

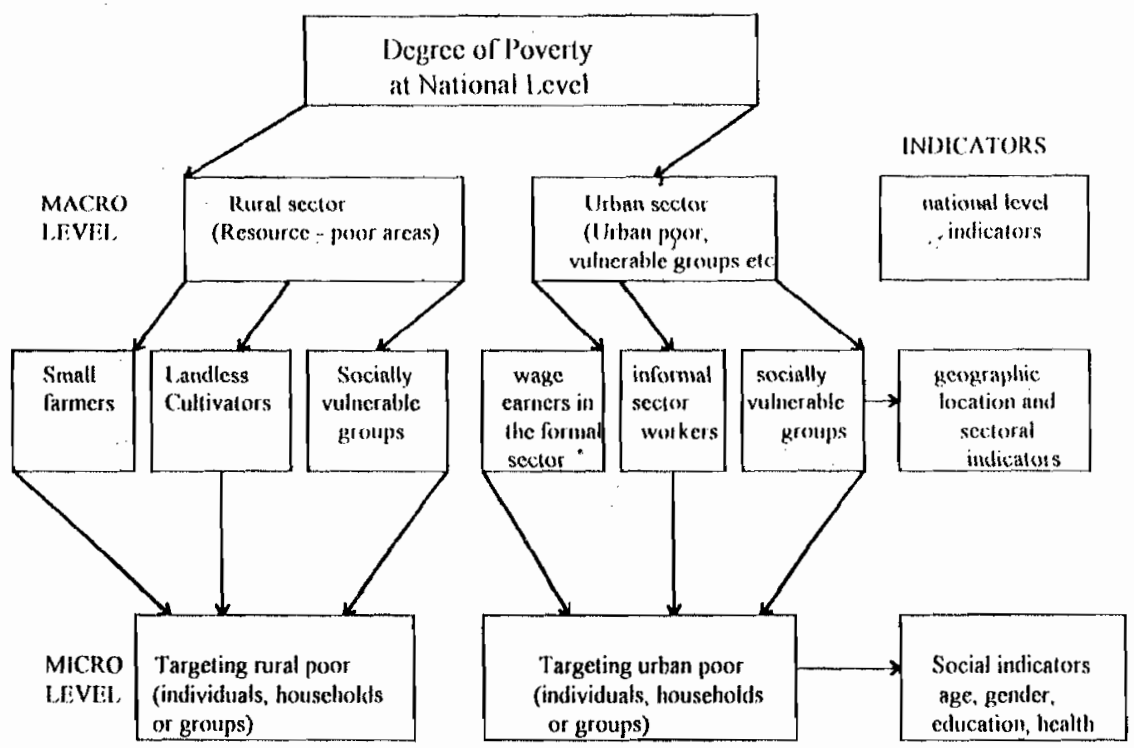

Figure 2: A conceptual model for targeting poverty in Sub-Saharan Africa 


\section{Targeting Policy Framework}

The above conceptual model for targeting poverty in Cameroon shows that action at the macro level consists of public policies. Middle range actions will contain. programmes targeted at groups, regions or specific sectors. Micro level activities will be projects designed, implemented and evaluated with the participation of the poor themselves.

The model also underscores the importance of uttacking poverty in both the formal and informal sectors as well as in rural and urban areas. The model also recognizes that poverty-reduction projects at the micro level can be directed at individuals or groups with specific unsatisfied basic needs.

The effectiveness of a poverty-reduction policy wil! depend on a clear identification of poverty groups: who they are, where they live, what they do for a living and the conditions under which they maintain their survival. As Nji (1992) has stated, policy-maker's lack of knowledge of the perceptions and problems of the poor lead to the design of unsuccessful projects based on ineffective policy structures. He points out also that the success of poverty alleviation programs in Africa will in the future still be determined by a careful integration of public policies and appropriate technologies for rural development. In his words, "... to arrest poverty, ignorance and disease in developing countries... scientists, policymakers and technologists (must) come to grips with the problems of lack of co-ordination in development programs and lack of understanding of rural people," (Nji, 1992: 42).

Three types of categories of the poor should be considered when designing targeted poverty-reduction programmes.

\section{1) Economically active poor}

Where the poor are economically active, incomes can be raised in at least three ways:

i) Improved access to resources such as land, credit,

ii) employment, income and agricultural inputs;

ii) Enhancing returns on these assets by lowering input prices, raising the prices of commodities produced by the poor, and 
removing market distortions for an efficient allocation of resources:

iii) The human capital of the poor can be improved by facilitating their access to education, health and social infrastructure.

These principles which are based on the theory of 'redistribution with growth: can be applied to the rural poor such as small-scale farmers, the landless, and workers in the informal sector.

\section{2) Physically handicapped, the ellderly or Disabled Poor}

These are people or groups that are unable to meet their basic needs through personal effort. Children, the elderly, disabled and physically impared fall in this group. For these groups, their conditions can only be improved through well-targeted policies and programs such as food aid, government subsides and transfers.

\section{The Need for decentralization of poverty reduction strategies}

In many societies, the poor are widely dispersed throughout the various sectors of the economy. In Sub-Saharan Africa and in other developing regions, the greatest concentrations of poor groups are to be found in rural areas and urban slums. To ensure that poverty-reduction actions reach these groups, it is imperative that all such action be decentralized and the responsibility for programme implementation invested in the hands of those who live closest to the poor and work with them directly.

This calls for viable active local power structures at local community levels. Such structures are necessary not only for participation in identifying the poor themselves, but also for designing, implementing and evaluating the impact of poverty reduction programmes. A policy of decentralization that is guided by democratic principles will ensure that there is participation from the grassroots and activities involvement of beneficiaries. Also, social services can be closely monitored and equitably delivered. In these circumstances, local organisations and elites will be able to play the important roles of development catalysts and facilitators that they are known to play in the development process of developing countries (Nkwi, 1997). 
Proponents of decentralization in poverty-reduction strategies argue that by bringing action to the grassroots, the problems of poor information, skewed incentives and benefit leakages that are typical with top-down methods of development can be overcome. This is based on the conviction that decentralization of the decision-making process within the context of genuine democracy makes decision-makers more accountabie and responsive to beneficiaries.

\section{Section IV - CONGLUSIONS}

The prevailing economic crisis in Cameroon and the Structural Adjustment Policies imposed by the international Monetary Fund have forced governments in Sub-Saharan Africa to re-examine the growth policies of the past, and encouraged them to begin to consider targeting as an alternative poverty-reduction strategy (World Bank, 1998). Although the targeting approach is being adopted very timidly, the message scientists get from this albeit shy adoption of policy-targeting is that governments will be willing to try new development paradigms that would lead to poverty reduction if government interests are protected, if government resources become scarce and, (unfortunately) only when politicians are pushed to the wall.

Income generation programmes are one of the ways by which SubSaharan African countries can target poverty. Labour-intensive public works programmes have the most promise to effect income transfers in exchange for labour as a way to reduce poverty. Unfortunately, many cash-strapped African countries lack the resources for public investments.

Yet, public works are an effective temporary measure to smooth consumption during economic shocks or natural disasters or in countries emerging from conflicts, where the need to rebuild infrastructure destroyed is great (World Bank, 1998:25). And since such income generating actions often require subsidies, it is important that poor countries inject planning values in their poverty-reduction programmes that include transparency, accountability, fiexibility, quality and affordability. 
Perhaps only a social and economic crisis of the magnitude being felt in Cameroon can joggle brains and bring reason and rationality back to the drawing board. But the readiness and conviction with which this is done at the level of policy-making is still fraught with scepticism, fear and a strong penchant for greed and entrenched corruption.

Genuine democracy is central to successful targeting policies. Education, awareness and a viable civil society are prerequisites to democratic governance. Decentralization prepares a favourable environment for effective targeting. Therefore, the successes and sustainability of poverty reduction strategies will depend on how well politicians, scientists and the governed can speak with one voice about problems that affect their common future. Can further research provide answers to these problems?

\section{REFERENCES}

Baliscan, A.M. 1996

"Political Economy of Poverty Alleviation" by Thimothy Besley. World Bank

Conference on Development Economics. PP 135-138.

Bardhan, P. 1995

"Research on Poverty and Development: Twenty Years Redistribution With

Growth" in: 1995 World Bank Conference on Development Economics:59-72.

Baeck, Louis. 1993

Post-war Development Theories and Practice. Cedex, France : UNESCO.

Biderman, Albert D. 1970

"Information, Intelligence, and Enlightened Public Policy: Functions and Organizations of Societal feedback." Policy Sciences l:217-230.

Boer, Leen, Dieke Buijs and Benno Galjart (eds.) 1985

Poverty and Interventions: Cases from Developing Countries. Leiden: University

of Leiden, Institute of Cultural and Social studies.

Chenery et al 1974

Redistribution With Growth. New York: Oxford University Press.

Foster J:, Greer I., and Thorbecke E., 1984

"A class of Decomposable Poverty Measures", Econometrica no 52, PP 716-65. Hammarskjold, Dag. 1975

Development Dialogue. Uppsala, Sweden : Author Lipton, Michael. 1977

The Urban Bias in Development: Why Poor People Stay Poor. New York: Free Press 
McIntosh, Wm. Alex, Gerald Klonglan and Leslie D. Wilcox. 1977

Theoretical Issues and Social Indicators: A Societal Process Approach. Policy

Sciences $8: 245-267$,

Meier G. M. ed. 1984

Leading Issues in Economic Development. New York : Oxford University Press Nkwi, Paul N. 1997

«Rethinking the Role of Elites in Rural Development: A Case Study from

Cameroon. 》Journai of Contemporary African Studies 15 (1): 67-86.

Njö, Ajagal 198 1

The Revitalization of Rural Communtties through integrated Rural development.

Buea, Cameroon: National Printing Press Annex.

$-1986$

Small is Possible and Efficient: An Empirical Verification of the Impact of Size

on the Utilization of Local Resources in Rural development Projects in

Cameroon. Science and technology Review IV (1-2) 57-70. $-1992$

The Dialectic between Appropriate Technology, Public Policy and Rural development. Discovery and Innovation 4(1) 33-45. 1994

Cameroon: Participatory Poverty Assessment: A Synthesis Report. Dschang, Cameroon. University of Dschang. $-1997$

Socio-cultural factors that determine the status of women in Cameroon. Paper presented at a seminar on Gender and Development, organized by Heifer Project International, Bamenda, Cameroon.

Nji, Ajaga and Mathias F. Fonteh. 1998

Farming Systems Analysis of Water Harvesting in the Far North Province of

Cameroon. Dschang, Cameroon,. FAO Consultancy Report.

Psacharopoulos, G. 1990

"Poverty Alleviation in Latin America". Finance \& Development 27 (1): 17-19.

Ravallion $M$, and M. Huppi 1991

"Measuring changes in Poverty Response: A Methodological Case Study of Indonesia During and Adjustment Period" in The Worid Bank Economic Review $5(1): 57-82$.

Sheldon, Eleanor B. and Hovard E. Freeman, 1974

"Social Indicators: Social Science Researchers are developing concepts and measures of changes in Society." Washington, D.C.: Center for Coordination of research on Social Indicators of the Social Science research Council

Smith. Adam. 1983

The Wealth of Nations (ed.) A. Skinner. London: Penguin Library. 
Streeten, Paul 1981

First Things First: Meeting Basic Needs in Developing Countries. New York:

Oxford University Press.

Thilswall, A. R. 1983

Growth and Development: With Special Reference to Developing Economies.

New York : Macmillan.

Wilcox, Leslie D., K. William Masson, Frank Fear, Gerald Klonglan and George M. Beal. 1976

Toward a Methodology for Social Indicators in Rural Development. Ames,

lowa: Department of Sociology and Anthropology.

World Bank. 1995

Cameroon: Diversity Growth and Poverty Reduction. Washington, D.C. Author. 1996

Taking Action to Reduce Poverty in Sub-Saharan African: An Overview. The World Bank. Wäshington DC : Author. 1998

Poverty Reduction and the World Bank: Progress in Fiscal 1996 and 1997. Washington, DC: Author. 